\title{
Prevalence and multilocus genotyping of Giardia duodenalis in pigs of Shaanxi Province, northwestern China
}

\author{
Sha-Sha Wang, Ya-Jie Yuan, Yan-Ling Yin, Rui-Si Hu, Jun-Ke Song and Guang-Hui Zhao*
}

\begin{abstract}
Background: Giardiasis, caused by Giardia duodenalis (syn. Giardia intestinalis, Giardia lamblia), is a significant zoonotic parasitic disease of animals and humans worldwide. Accurate genotyping of $G$. duodenalis is essential for efficient control and management of giardiasis. The objectives of the present study were to investigate the prevalence and assemblages of giardiasis in pigs in Shaanxi Province, northwestern China, and for the first time study multilocus genotypes (MLGs) in pigs using multilocus genotyping technology in this region.

Results: Of 560 faecal samples collected from five farms in Shaanxi Province, 45 were positive for G. duodenalis and significant differences in prevalence were observed among different locations. Differences in prevalence were also detected in pigs of different age groups, with the highest prevalence in sows and the lowest in boars. Two assemblages, $A$ and $E$, were identified, and a mixed infection of both $A$ and $E$ was identified in one faecal sample. Assemblage $E$ was predominant and widely distributed in all investigated areas and age groups. Genetic viability was detected for both assemblages, and four different multi-locus genotypes (MLGs) within assemblage E were found, MLGE1-MLGE4.
\end{abstract}

Conclusions: Giardia duodenalis was detected in pigs from Shaanxi Province, northwestern China, and genetic diversity was observed in these infections. Both assemblages $A$ and $E$ were detected, and four distinct MLGs within assemblage $E$ were identified. These findings provide new data for controlling G. duodenalis infection in pigs.

Keywords: Giardia duodenalis, Prevalence, MLG, Pig, Shaanxi Province, China

\section{Background}

Giardia duodenalis (syn. Giardia intestinalis, Giardia lamblia), an important parasitic protozoan, inhabits the gastrointestinal tracts of animals. It causes giardiasis, with clinical presentations ranging from chronic to acute diarrhea, dehydration, abdominal pain, nausea, vomiting, and weight loss [1], leading to large economic impacts [2]. Giardiasis is mainly transmitted through the faecal-oral route (e.g. water or food) [3]. The public health impact of giardiasis is significant because of its tendency to cause major outbreaks and its adverse effects on growth and cognitive functions in children $[4,5]$. Giardia duodenalis has also been reported in a wide variety of other hosts worldwide, including sheep, goats, cattle, and non-human primates [6-20].

\footnotetext{
* Correspondence: zgh083@nwsuaf.edu.cn

College of Veterinary Medicine, Northwest A\&F University, 22 Xinong Road, Yangling 712100, People's Republic of China
}

Recent molecular analysis indicated eight major morphologically similar but genetically distinct assemblages of G. duodenalis, assemblages A-H [21]. Among them, assemblages $A$ and $B$ have been identified in both humans and animals [13], whereas the remaining six assemblages $(\mathrm{C}-\mathrm{H})$ infect non-human hosts; however, assemblages $\mathrm{C}$, $\mathrm{D}, \mathrm{E}$, and $\mathrm{F}$ have also been identified in humans $[2,22]$.

In China, G. duodenalis has been identified in sheep $(4.3-6.6 \%)[15,16]$, goats $(2.9-12.7 \%)[16,17]$ and cattle (1.1-60.1\%) [19-21]. Although most infections were asymptomatic, cysts excreted in faeces could be a possible source of infection for humans and other animals [23]. Pigs are an economically important food animal, providing pork to many nations, and pig manure is sometimes used in the cultivation of food and feed crops [24]. Giardia duodenalis infection has been reported in pigs in many countries (Table 1), with the zoonotic assemblages A and B have been detected in pigs [25], suggesting that pigs may be a reservoir of human infection. China is recognized as the largest 
Table 1 Global prevalence of Giardia duodenalis infection in pigs

\begin{tabular}{|c|c|c|c|c|c|c|}
\hline Country (City) & No. examined & Prevalence (\%) & Locus & Detection method & Time tested (year) & Reference \\
\hline Australia (unknown) & 289 & 31.1 & SSU rRNA & PCR & $2005-2006$ & [41] \\
\hline Canada (Edward) & 633 & 1.0 & SSU rRNA, bg & Immunofluorescence microscopy and PCR & 2007 & [48] \\
\hline Canada (Ontario) & 122 & 66.4 & SSU rRNA, bg & Immunofluorescence microscopy and PCR & $2005-2006$ & [42] \\
\hline Canada (unknown) & 236 & 9.0 & $-{ }^{a}$ & Immunofluorescence microscopy & 1995 & [54] \\
\hline Cambodia (Preah Vihear) & 76 & 0 & SSU rRNA & Immunofluorescence microscopy and PCR & 2012 & [49] \\
\hline China (Shaanxi) & 560 & 8 & bg, tpi, gdh & PCR & $2016-2017$ & This study \\
\hline Denmark (unknown) & 1237 & 17.4 & $--^{a}$ & Immunofluorescence microscopy & 2003-2004 & [43] \\
\hline Denmark (unknown) & 856 & 14.0 & SSU rRNA, gdh & Immunofluorescence microscopy and PCR & $2011-2012$ & [44] \\
\hline Denmark (unknown) & 1237 & 17.4 & SSU rRNA, gdh & PCR & $2003-2004$ & [45] \\
\hline Turkey (Istanbul) & 238 & 3.7 & $-{ }^{a}$ & Immunofluorescence microscopy & 2005 & [50] \\
\hline Norway (unknown) & 684 & 1.5 & SSU rRNA & Immunofluorescence microscopy and PCR & 2004-2005 & [51] \\
\hline Poland (unknown) & 84 & 9.5 & $b g$ & Immunofluorescence microscopy and PCR & 2013-2014 & [46] \\
\hline UK (Preston, Cheshire) & 7 & 57.1 & SSU rRNA & PCR & $2007-2008$ & [47] \\
\hline USA (Ohio) & 325 & 7.4 & $-{ }^{a}$ & Immunofluorescence microscopy & 1993 & [52] \\
\hline Zambia (Lusaka) & 217 & 12.0 & $--^{a}$ & Immunofluorescence microscopy & 2011 & [25] \\
\hline
\end{tabular}

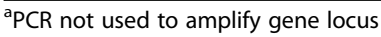

pig breeding country in the world, with about 667 million pigs produced annually, however, prior to the present study, no public reports on $G$. duodenalis infection in pigs of China were available.

Previous studies to investigate G. duodenalis used morphological methods or molecular technologies based on one or two gene loci (Table 1). Morphological examination is time- and labor-consuming, and cannot identify assemblages [26]. Molecular assay using one or two gene loci could not differentiate mixed infectious and did not provide sufficient information to understand the possible zoonotic links [27]. Recently, a multilocus genotyping technique was developed and has been applied to genotype G. duodenalis in dairy calves [28], native beef calves [20], sheep [15], raccoon dogs [29], children [30], pet chinchillas [31], red deer, roe deer [32] and other hosts [33]. Using four gene loci, namely $\beta$-giardin $(b g)$, glutamate dehydrogenase $(g d h)$, triosephosphate isomerase (tpi) and the small subunit ribosomal RNA (SSU rRNA), several multilocus genotypes (MLGs) and mixed genotypes were observed, including one MLGA and four MLGE in dairy calves [28], one MLGA, twenty-two MLGE and two mixed A + E in native beef calves [20], one MLGA, six MLGE and three mixed in sheep [15], three MLGC in raccoon dogs [29], two MLGA and three MLGE in pet chinchillas [31], and two MLGA and nine MLGE in children [30]. The objectives of the present study were to determine the prevalence and assemblages of G. duodenalis in pigs in Shaanxi Province, northwestern China, and investigate the MLGs in pigs using multilocus genotyping tool.

\section{Methods}

\section{Sample collection}

Shaanxi Province is located across the Qinling Mountains, which is the border between the North and South of China. It has gradually become one of the important regions of the pig industry due to environmental pollution and disease epidemics in the traditional pig breeding areas in northern China. In 2016, there were 3901 large pig farms operating in Shaanxi Province. In order to determine the prevalence and assemblage distribution of G. duodenalis in pigs in Shaanxi Province, northwestern China, 560 faecal samples were collected from pigs (newborn to 2 years) from five different farms in Zhouzhi, Qishan, Mianxian, Lintong and Yuyang, between September 2016 and March 2017 (Fig. 1). The 560 faecal samples comprised samples from suckling piglets aged $<25$ days, weaned piglets aged $1-4$ months, fatteners aged 4-6 months, and sows and boars aged 6 months to 2 years. Fresh normal faeces were randomly sampled from apparently healthy pigs of all age groups and for whom antibiotics or other antimicrobials were not used. Samples were placed into individual sterile plastic containers, marked with the geographical origin, date, breed, age and sample number. All faecal samples were then transported immediately to the laboratory on ice packs, preserved in $2.5 \%$ potassium dichromate and stored at $4{ }^{\circ} \mathrm{C}$ for further analysis.

\section{Genomic DNA extraction}

Each faecal sample was washed three times in distilled water with centrifugation at 13,000 rpm for $1 \mathrm{~min}$ to remove the potassium dichromate. Genomic DNA of each 


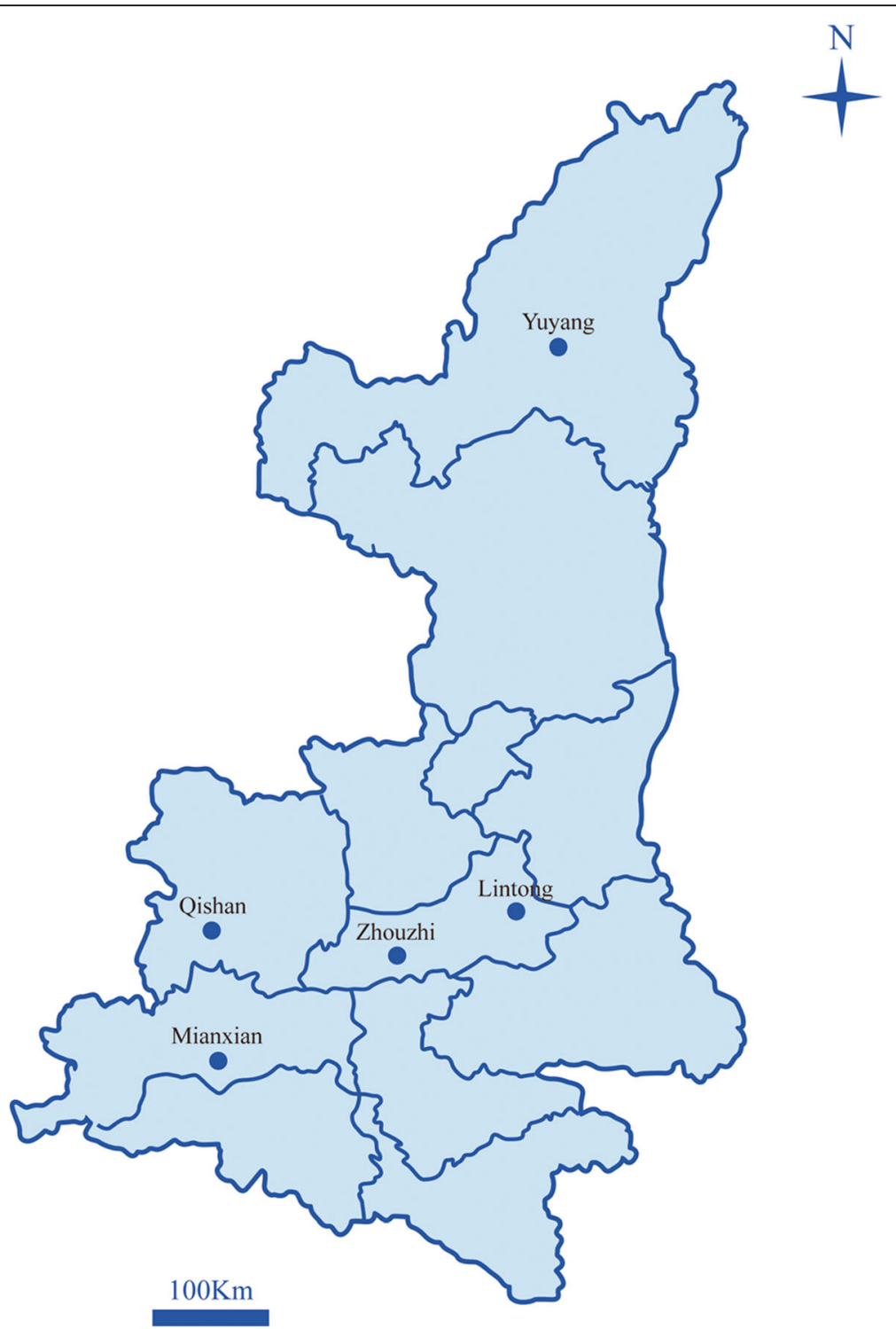

Fig. 1 Sampling sites in this study

sample was extracted from approximately $300 \mathrm{mg}$ of washed faecal material, using the commercial E.Z.N.A ${ }^{\circ}$ Stool DNA kit (Omega Bio-Tek Inc., Norcross, GA, USA), according to the manufacturer's instructions. Extracted DNA samples were stored at $-20^{\circ} \mathrm{C}$ prior to PCR analysis.

\section{Nested PCR amplification}

The prevalence of $G$. duodenalis in pigs was initially determined by nested PCR targeting the $b g$ gene fragment using primers described previously [34] in a $25 \mu \mathrm{l} \mathrm{PCR} \mathrm{mixture}$ containing $1 \mu$ genomic DNA (for the primary PCR) or $1 \mu \mathrm{l}$ of the primary amplification product (for the secondary PCR) as the template, $2.5 \mu \mathrm{l} 10 \times$ Ex Taq Buffer $\left(\mathrm{Mg}^{2+}\right.$ free), $2 \mathrm{mM} \mathrm{MgCl}_{2}, 0.2 \mathrm{mM}$ dNTP Mixture, $0.625 \mathrm{U}$ of TaKaRa
Ex Taq (TaKaRa Shuzo Co., Ltd) and 0.4 $\mu \mathrm{M}$ of each primer (Table 2).

To investigate multi-locus genotypes (MLGs) of G. duodenalis in pigs, the $b g$-positive samples were then amplified using primers for the $g d h$ and tpi gene loci described previously $[34,35]$ (Table 2). The PCR products were then examined by electrophoresis in 1\% $(w / v)$ agarose gels with ethidium bromide staining.

\section{Sequencing and sequence analysis}

All positive PCR products were sent to Xian Qingke Biological Co., Ltd. for direct sequencing on an ABI PRISM 3730 XL DNA Analyzer (Applied Biosystems, Foster City, CA, USA) using relevant internal nested primers for PCR amplification. Sequences obtained were aligned with 
Table 2 PCR primers used in this study

\begin{tabular}{|c|c|c|c|c|c|}
\hline Gene locus & Primer name & Sequence $\left(5^{\prime}-3^{\prime}\right)$ & Amplicon length (bp) & Annealing temperature $\left({ }^{\circ} \mathrm{C}\right)$ & Reference \\
\hline \multirow[t]{4}{*}{$b g$} & G7-F & TCAACGTYAAYCGYGGYTTCCGT & 573 & 52 & {$[35]$} \\
\hline & G759-R & CAGTACACCTCYGCTCTCGG & & & \\
\hline & G99-F & GAACGAACGAGATCGAGGTCCG & 511 & 55 & \\
\hline & G609-R & CTCGACGAGCTTCGTGTT & & & \\
\hline \multirow[t]{4}{*}{ tpi } & AL3543 & AAATIATGCCTGCTCGTCG & 605 & 50 & [34] \\
\hline & AL3546 & CAAACCTTITCCGCAAACC & & & \\
\hline & AL3544 & CCCTTCATCGGIGGTAACTT & 530 & 58 & \\
\hline & AL3545 & GTGGCCACCACICCCGTGCC & & & \\
\hline \multirow[t]{4}{*}{$g d h$} & GDHeF & TCAACGTYAAYCGYGGYTTCCGT & 432 & 52 & [35] \\
\hline & GDHeR & GTTRTCCTTGCACATCTCC & & & \\
\hline & GDHiF & CAGTACACCTCYGCTCTCGG & 432 & 65 & \\
\hline & GDHiR & GTTRTCCTTGCACATCTCC & & & \\
\hline
\end{tabular}

sequences available on GenBank using Basic Local Alignment Search Tool (BLAST), and edited using DNAStar 5.0 [36] and Clustal X 1.81 [37]. Giardia duodenalis assemblages were identified by their alignment to reference sequences available from GenBank. MLGs were identified for samples which were successfully sequenced at all three loci.

\section{Statistical analysis}

Chi-square $\left(\chi^{2}\right)$ analysis and 95\% confidence intervals (CIs) were calculated using SPSS 19.0 for Windows (SPSS Inc., Chicago, IL, USA) and used to analyze differences between different locations and age groups, with $P<0.05$ considered statistically significant.

\section{Nucleotide sequence accession numbers}

All nucleotide sequences obtained in this study were submitted to the National Center for Biotechnology Information (NCBI) GenBank database under the following accession numbers: KY989575-KY989579 for the bg gene, KY989580KY989583 for the tpi gene, and MF034655-MF034658 for the $g d h$ gene.

\section{Results and discussion}

Globally, Giardia duodenalis is one of the most common intestinal parasites in symptomatic and asymptomatic humans and livestock [38]; this species is relatively common in pigs worldwide (Table 1). Although no clinical signs are observed in most pigs carrying $G$. duodenalis, they still shed infective G. duodenalis cysts into the environment which can survive for extended periods in cool, humid environments. Considering that exposure to infective cysts through contaminated water and food is the primary mechanism of G. duodenalis transmission to animals and humans $[39,40]$, investigating G. duodenalis infection in pigs has important implications for controlling giardiasis in humans and animals.

Varying prevalence rates of G. duodenalis have been reported in livestock in China, e.g. 4.3-6.6\% in sheep [14-16],
$2.9-12.7 \%$ in goats $[16,17]$ and $1.1-60.1 \%$ in cattle [18-20]. In the present study, of the 560 faecal samples examined from five locations, 45 (8\%, 95\% CI: 7.4-8.7\%) were positive for $G$. duodenalis infection (Table 3). Significantly different $\left(\chi^{2}=28.514, d f=4, P<0.0001\right)$ prevalences were observed among different locations, with the highest $(16.7 \%, 17 / 102)$ in Lintong district and the lowest $(1.0 \%, 1 / 100)\left(\chi^{2}=13.909\right.$, $d f=1, P<0.01)$ in Qishan county. Comparison of these results with results obtained from other pig farms showed that the prevalence of G. duodenalis in pigs in Shaanxi Province in China was lower than that in Australia (31.1\%) [41], Ontario, Canada (66.4\%) [42], Denmark (14.0-17.4\%) [43-45], Poland (9.5\%) [46], Lusaka, Zambia (12.0\%) [25], and Preston and Cheshire, UK (57.1\%) [47], but higher than in Prince Edward Island, Canada (1.0\%) [48], Preah Vihear, Cambodia (0) [49], Istanbul, Turkey (3.7\%) [50], Norway (1.5\%) [51] and Ohio, USA (7.4\%) [52]. The differences are probably due to a range of factors, including the presence of other animal species on the farm, examination methods, study design, number of samples analysed, time of specimen collection, environmental conditions and farm management practices $[28,53]$. For example, slightly higher prevalences were observed from some pig farms with multiple animal species raised in the same farms (e.g. 57.1\% in the UK) (Table 1). In our study, two farms from Mianxian and Lintong also housed dogs and ducks, and the prevalence of G. duodenalis was comparatively higher (9.0\% and $16.7 \%$, respectively). These findings could suggest transmission between the different animals, which should be explored in future studies.

Differences in G. duodenalis prevalence were detected in pigs of different age groups in this study, but these differences were not statistically significant $\left(\chi^{2}=2.056, d f=4\right.$, $P>0.05)$. The highest prevalence $\left(10.5 \%, \chi^{2}=1.264, d f=1\right.$, $P>0.05)$ was detected in sow pigs, which was consistent with a study from Zambia (53.3\%) [25], but was different to a study performed in Australia (30.0\%) [41] and one study from Denmark (14.0\%) [44], where the highest prevalence 
Table 3 Prevalence and factors associated with G. duodenalis infection in pigs in Shaanxi Province, northwestern China

\begin{tabular}{|c|c|c|c|c|c|c|}
\hline \multirow[t]{2}{*}{ Variable } & \multirow[t]{2}{*}{ Category } & \multirow[t]{2}{*}{ No. examined } & \multirow[t]{2}{*}{ No. positive (\%) } & \multicolumn{3}{|c|}{ Target locus (no. positive) } \\
\hline & & & & bg & tpi & gdh \\
\hline \multirow[t]{6}{*}{ Age } & Suckling piglest & 155 & $10(6.5)$ & 10 & 4 & 5 \\
\hline & Weaned pigs & 220 & $20(9.1)$ & 20 & 8 & 4 \\
\hline & Fatteners & 98 & $8(8.2)$ & 8 & 6 & 2 \\
\hline & Sow & 57 & $6(10.5)$ & 6 & 2 & 0 \\
\hline & Boar & 30 & $1(3.3)$ & 1 & 0 & 0 \\
\hline & Total & 560 & $45(8.0)$ & 45 & 20 & 11 \\
\hline \multirow[t]{6}{*}{ Location** } & Zhouzhi county & 143 & $2(1.4)$ & 2 & 1 & 0 \\
\hline & Qishan county & 100 & $1(1.0)$ & 1 & 0 & 0 \\
\hline & Mianxian county & 100 & $9(9.0)$ & 9 & 5 & 3 \\
\hline & Lintong district & 102 & $17(16.7)$ & 17 & 12 & 4 \\
\hline & Yuyang district & 115 & $16(13.9)$ & 16 & 2 & 4 \\
\hline & Total & 560 & $45(8.0)$ & 45 & 20 & 11 \\
\hline
\end{tabular}

${ }^{* * P}<0.0001$

was found in weaned pigs. The second highest prevalence (9.1\%) was observed in weaned pigs and the lowest infection rate was found in boars, with a prevalence of $3.3 \%$, which was different with a study in Zambia [25], in which the sucking piglets had the lowest infection rate (25\%). Although previous studies have suggested that the immunity, nutritional status, geographical separation and gut microbiome could contribute to the variable prevalence in pigs of different age groups [44], the actual association between pig age and G. duodenalis infection should be further evaluated in future studies.

Genetic variability of $G$. duodenalis has been reported in pigs and five assemblages (A, B, D, E, F) have been reported [41, 42, 44-46]. In the present study, two assemblages, A and E, were detected among 45 G. duodenalispositive samples based on the $b g$ gene, with assemblage $\mathrm{E}$ $(80 \%, 36 / 45)$ being the predominant assemblage, which was detected in all investigated areas and age groups. These results were consistent with a study in Australia [41] and two studies from Denmark [44, 45]. Additionally, the highest prevalence of the assemblage $\mathrm{E}$ was observed in weaned pigs in our study and studies in Denmark [44] and Australia [41]. While assemblage A $(20 \%, 9 / 45)$ was only found in pigs from Zhouzhi county, Lintong district and Yuyang district, it was widely distributed in all age groups except boars. The reason from the higher prevalence of assemblage A in these specific locations is worthy of further investigation. Comparison with previous studies $[41,42,44,45]$ also indicated that this was the first report for assemblage A in sow.

To further illuminate the genetic diversity of G. duodenalis in pigs, the sequence characters of the tpi and $g d h$ genes were analyzed for the $45 \mathrm{bg}$ positive samples and the MLGs were characterized in pigs using combined data from these three gene loci. Of $45 \mathrm{bg}$-positive samples, $9 \mathrm{tpi}$ and $11 \mathrm{gdh}$ gene sequences were obtained. Sequence alignment identified different genotypes of assemblages $\mathrm{E}$ (Table 4) and A (Table 5). Eight faecal samples of assemblage $\mathrm{E}$ were successfully sequenced at all three gene loci, forming four different assemblage E MLGs, named as MLGE1-MLGE4 (Table 6). MLGE1 and MLGE4 were only found in weaned pigs from Mianxian county and fatteners from Yuyang district, respectively. Both MLGE2 and MLGE3 were detected in pigs from Lintong district, but they were distributed in different age groups, with MLGE2 in suckling pigs and MLGE3 in both weaned pigs and fatteners. Although no zoonotic assemblage A MLGs were obtained in our study, a mixed assemblage of

Table 4 Intra-assemblage substitutions in bg, tpi and gdh sequences from assemblage $\mathrm{E}$

\begin{tabular}{|c|c|c|c|c|c|}
\hline \multirow[t]{2}{*}{ Subtype (number) } & \multicolumn{4}{|c|}{ Nucleotide positions and substitutions } & \multirow[t]{2}{*}{ GenBank ID } \\
\hline & 57 & 120 & \multicolumn{2}{|l|}{180} & \\
\hline \multicolumn{6}{|l|}{$b g$} \\
\hline Ref. sequence & T & C & C & & KU668892 \\
\hline \multirow[t]{2}{*}{ E (36) } & $\mathrm{T}$ & C & C & & KY989575 \\
\hline & 56 & 143 & 340 & & \\
\hline \multicolumn{6}{|l|}{ tpi } \\
\hline Ref. sequence & C & C & C & & KJ668136 \\
\hline E1 (6) & C & C & C & & KY989581 \\
\hline E2 (8) & C & T & C & & KY989580 \\
\hline \multirow[t]{2}{*}{ E3 (1) } & C & C & $\mathrm{T}$ & & KY989582 \\
\hline & 68 & 216 & 285 & 303 & \\
\hline \multicolumn{6}{|l|}{ gdh } \\
\hline Ref. sequence & T & T & C & C & JN160739 \\
\hline E1 (5) & $\mathrm{T}$ & $C$ & $C$ & $\mathrm{~T}$ & MF034655 \\
\hline E2 (3) & T & T & $\mathrm{T}$ & $C$ & MF034657 \\
\hline E3 (2) & $\mathrm{T}$ & $\mathrm{T}$ & $\mathrm{T}$ & C & MF034658 \\
\hline
\end{tabular}


Table 5 Intra-assemblage substitutions in tpi, gdh and bg sequences from assemblage A

\begin{tabular}{ccccccc}
\hline Subtype (number) & \multicolumn{7}{c}{ Nucleotide positions and substitutions } & GenBank ID \\
\cline { 2 - 5 } & 58 & 122 & 255 & 269 & 307 & \\
\hline bg & & & & & & \\
Ref. sequence & C & C & A & A & C & KT728529 \\
A1 (4) & T & C & A & A & T & KY989576 \\
A2 (3) & C & C & A & A & C & KY989577 \\
A3 (1) & C & T & A & G & C & KY989578 \\
A4 (1) & C & C & G & A & C & KY989579 \\
tpi & 8 & 120 & 180 & 240 & 300 & \\
Ref. sequence & C & A & G & A & A & KU382249 \\
A (5) & C & A & G & A & A & KY989583 \\
gdh & 56 & 120 & 180 & 240 & 300 & \\
Ref. sequence & T & T & C & C & G & JF792402 \\
A (1) & T & T & C & C & G & MF034656 \\
\hline
\end{tabular}

$E$ and $A$ infections was found in one isolate (LTD6) from fatteners in Lintong district, which would be the result of mixed infection or genetic exchange between assemblages [20]. Previous studies also detected mixed infections of these two assemblages in pigs from Denmark based on $g d h$ and SSU rRNA sequences [44] and other reports using $b g$, gdh, tpi, and SSU rRNA sequences in dairy calves [28], dairy cattle [20], and sheep [15]. This suggests that multilocus genotyping would be an accurate tool to determine mixed infections, zoonotic potential and genetic variability of $G$. duodenalis in animals as well as humans.

Table 6 Multilocus characterization of Giardia isolates based on the $b g$, tpi and gdh genes

\begin{tabular}{|c|c|c|c|c|}
\hline \multirow[t]{2}{*}{ Isolate } & \multicolumn{3}{|c|}{ Genotype or subtype } & \multirow{2}{*}{$\begin{array}{l}\text { MLG } \\
\text { type }\end{array}$} \\
\hline & bg & tpi & gdh & \\
\hline ZZF6, LTB12, LTD2 & E & E1 & $-^{a}$ & - \\
\hline HZB5, HZB11, HZB19 & E & E2 & E1 & MLGE1 \\
\hline HZB20, HZC9, LTA7 & E & E2 & $-{ }^{a}$ & - \\
\hline LTA4, LTA18 & E & E2 & E2 & MLGE2 \\
\hline LTB7, LTD10 & $E$ & E1 & E1 & MLGE3 \\
\hline LTB10 & E & E3 & $-{ }^{a}$ & - \\
\hline LTD6 & E & A & $--_{a}$ & Mixed \\
\hline LTD9, LTE14, LTE15 & $\mathrm{A} 1$ & A & $--^{a}$ & - \\
\hline YLA4 & $\mathrm{A} 2$ & $-{ }^{a}$ & $A$ & - \\
\hline YLA21 & E & $-{ }^{a}$ & E2 & - \\
\hline YLA24 & $E$ & $-{ }^{a}$ & E3 & - \\
\hline YLA35 & $\mathrm{A} 2$ & A & $-{ }^{a}$ & - \\
\hline YLD13 & E & E1 & E3 & MLGE4 \\
\hline
\end{tabular}

${ }^{\mathrm{a}}$ No amplification

\section{Conclusions}

The prevalence and MLGs of G. duodenalis in pigs from Shaanxi Province, northwestern China, were investigated in the present study. The total prevalence of G. duodenalis infection was $8 \%$ and the highest infection rate was observed in sow. Assemblage analysis indicated the presence of the animal-specific assemblage $\mathrm{E}$ and the potentially zoonotic assemblage A. Genetic diversity was found within both assemblages, and four assemblage E MLGs were discovered. To the best of our knowledge, this is the first investigation of G. duodenalis MLGs in pigs. The findings in our study provided basic data for understanding the molecular epidemiology of G. duodenalis in pigs, and highlighted the significance of multilocus genotyping for unraveling the intricate molecular epidemiology of giardiasis in animals and impact on livestock economics and human health. However, there were some limitations to the sampling strategies and study methodologies in our study. For example, no statistical analysis of prevalence in different seasons was conducted in our study. Therefore, additional factors should be included in future studies to accurately determine the infection status of $G$. duodenalis in pigs in Shaanxi Province as well as other geographical locations.

\section{Abbreviations}

Bg: $\beta$-giardin; Gdh: glutamate dehydrogenase; MLGs: multilocus genotyping; SSU rRNA: small subunit ribosomal RNA; Tpi: triosephosphate isomerase

\section{Acknowledgments}

We would like to thank Zheng-Qing Yu and Hun-Jun Zhang for collecting samples, and Professor Una Ryan in School of Veterinary and Life Sciences, Murdoch University, Murdoch, WA, Australia, for copyediting our MS.

\section{Funding}

This work was supported, in part, by the Science and Technology Project of Shaanxi Province (2016NY-113). The funders had no role in study design, data collection and analysis, decision to publish, or preparation of the manuscript.

\section{Availability of data and materials}

The datasets supporting the conclusions of this article are included within the article. Representative sequences are submitted to the GenBank database under the following accession numbers: KY989575-KY989579, KY989580KY989583 and MF034655-MF034658.

\section{Authors' contributions}

GHZ conceived and designed the experiments. SSW, JKS, YJY, RSH and YLY conducted the sample collection and the molecular genetic studies. SSW and $\mathrm{GHZ}$ performed the sequence analyzes. SSW and GHZ wrote and corrected the manuscript. All authors read and approved the final manuscript.

\section{Ethics approval}

The study was conducted and implemented in accordance with the Guide for the Care and Use of Laboratory Animals of the Ministry of Health, China and approved by the internal review board of the Research Ethics Committee of Northwest Agriculture and Forestry University, Yangling, China. All procedures performed in studies involving the collection of fecal samples were permitted by the farm owners.

Consent for publication

Not applicable.

Competing interests

The authors declare that they have no competing interests. 


\section{Publisher's Note}

Springer Nature remains neutral with regard to jurisdictional claims in published maps and institutional affiliations.

Received: 15 May 2017 Accepted: 3 October 2017

Published online: 17 October 2017

\section{References}

1. Nissapatorn V, Lim YA, Jamaiah I, Agnes LS, Amyliana K, Wen CC, et al. Parasitic infections in Malaysia: changing and challenges. Southeast Asian J Trop Med Public Health. 2005:36(Suppl 4):50-9.

2. Feng Y, Xiao L. Zoonotic potential and molecular epidemiology of Giardia species and giardiasis. Clin Microbiol Rev. 2011;24:110-40.

3. Koehler AV, Jex AR, Haydon SR, Stevens MA, Gasser RB. Giardia/giardiasis - a perspective on diagnostic and analytical tools. Biotechnol Adv. 2014;32:280-9.

4. Hibbard JH, Berkman N, McCormack LA, Jael E. The impact of a CAHPS report on employee knowledge, beliefs, and decisions. Med Care Res Rev. 2002;59:104-16

5. Halliez MC, Buret AG. Extra-intestinal and long term consequences of Giardia duodenalis infections. World J Gastroenterol. 2013:19:8974-85.

6. Tzanidakis N, Sotiraki S, Claerebout E, Ehsan A, Voutzourakis N, Kostopoulou $D$, et al. Occurrence and molecular characterization of Giardia duodenalis and Cryptosporidium spp. in sheep and goats reared under dairy husbandry systems in Greece. Parasite. 2014;21:45.

7. Paz e Silva FM, Lopes RS, Bresciani KD, Amarante AF, Araujo JP Jr. High occurrence of Cryptosporidium ubiquitum and Giardia duodenalis genotype $E$ in sheep from Brazil Acta Parasitol 2014;59:193-196.

8. Ruiz A, Foronda P, González JF, Guedes A, Abreu-Acosta N, Molina JM, Valladares B. Occurrence and genotype characterization of Giardia duodenalis in goat kids from the Canary Islands, Spain. Vet Parasitol. 2008;154:137-41.

9. Matsuura Y, Matsubayashi M, Nukata S, Shibahara T, Ayukawa O, Kondo Y, et al. Report of fatal mixed infection with Cryptosporidium parvum and Giardia intestinalis in neonatal calves. Acta Parasitol. 2017:62:214-20.

10. Lee SH, VanBik D, Kim HY, Cho A, Kim JW, Byun JW, et al. Prevalence and molecular characterisation of Giardia duodenalis in calves with diarrhoea. Vet Rec. 2016;178:633.

11. Sricharern W, Inpankaew T, Keawmongkol S, Supanam J, Stich RW Jittapalapong S. Molecular detection and prevalence of Giardia duodenalis and Cryptosporidium spp. among long-tailed macaques (Macaca fascicularis) in Thailand. Infect Genet Evol. 2016:40:310-4.

12. Berrilli F, Prisco C, Friedrich KG, Di Cerbo P, Di Cave D, De Liberato C. Giardia duodenalis assemblages and Entamoeba species infecting non-human primates in an Italian zoological garden: zoonotic potential and management traits. Parasit Vectors. 2011:4:199.

13. Asher AJ, Hose G, Power ML. Giardiasis in NSW: identification of Giardia duodenalis assemblages contributing to human and cattle cases, and an epidemiological assessment of sporadic human giardiasis. Infect Genet Evol. 2016:44:157-61.

14. Ye J, Xiao L, Wang Y, Guo Y, Roellig DM, Feng Y. Dominance of Giardia duodenalis assemblage a and Enterocytozoon bieneusi genotype BEB6 in sheep in Inner Mongolia, China. Vet Parasitol. 2015;210:235-9.

15. Wang H, Qi M, Zhang K, Li J, Huang J, Ning C, Zhang L. Prevalence and genotyping of Giardia duodenalis isolated from sheep in Henan Province, central China. Infect Genet Evol. 2016;39:330-5

16. Zhang W, Zhang X, Wang R, Liu A, Shen Y. Ling het al. Genetic characterizations of Giardia duodenalis in sheep and goats in Heilongjiang Province, China and possibility of zoonotic transmission. PLoS Negl Trop Dis. 2012;6:e1826.

17. Peng XQ, Tian GR, Ren GJ, ZQ Y, Lok JB, Zhang LX, et al. Infection rate of Giardia duodenalis, Cryptosporidium spp. and Enterocytozoon bieneusi in cashmere, dairy and meat goats in China. Infect Genet Evol. 2016:41:26-31.

18. Wang $X$, Cai $M$, Jiang W, Wang $Y$, Jin $Y$, Li N, et al. High genetic diversity of Giardia duodenalis assemblage $E$ in pre-weaned dairy calves in shanghai, China, revealed by multilocus genotyping. Parasitol Res. 2017:116:2101-10.

19. Li F, Wang H, Zhang Z, Li J, Wang C, Zhao J, et al. Prevalence and molecular characterization of Cryptosporidium spp. and Giardia duodenalis in dairy cattle in Beijing, China. Vet Parasitol. 2016;219:61-5.

20. Wang XT, Wang RJ, Ren GJ, ZQ Y, Zhang LX, Zhang SY, Lu H, Peng XQ, Zhao GH. Multilocus genotyping of Giardia duodenalis and Enterocytozoon bieneusi in dairy and native beef (Qinchuan) calves in Shaanxi Province, northwestern China. Parasitol Res. 2016;115:1355-61.
21. Heyworth MF. Giardia duodenalis genetic assemblages and hosts. Parasite. 2016:23:13.

22. Ryan U, Cacciò SM. Zoonotic potential of Giardia. Int J Parasitol. 2013;43:943-56.

23. Adamska M. Molecular characterization of Cryptosporidium and Giardia occurring in natural water bodies in Poland. Parasitol Res. 2015;114:687-92.

24. Hutchison ML, Walters LD, Avery SM, Synge BA, Moore A. Levels of zoonotic agents in British livestock manures. Lett Appl Microbiol. 2004;39:207-14.

25. Siwila J, Mwape KE. Prevalence of Cryptosporidium spp. and Giardia duodenalis in pigs in Lusaka, Zambia. Onderstepoort J Vet Res. 2012;79:E1-5.

26. Zechmann B, Graggaber G, Zellnig G. Microwave assisted rapid diagnosis of plant virus diseases by transmission electron microscopy. J Vis Exp. 2011;56:e2950.

27. Lebbad M, Mattsson JG, Christensson B, Ljungström B, Backhans A, Andersson JO, Svärd SG. From mouse to moose: multilocus genotyping of Giardia isolates from various animal species. Vet Parasitol. 2010;168:231-9.

28. Qi M, Wang H, Jing B, Wang R, Jian F, Ning C, Zhang L. Prevalence and multilocus genotyping of Giardia duodenalis in dairy calves in Xinjiang, northwestern China. Parasit Vectors. 2016:9:546.

29. Zhang XX, Zheng WB, Ma JG, Yao QX, Zou Y, Bubu CJ, et al. Occurrence and multilocus genotyping of Giardia intestinalis assemblage $C$ and $D$ in farmed raccoon dogs, Nyctereutes procyonoides, in China. Parasit Vectors. 2016;9:471.

30. Wegayehu T, Karim MR, Li J, Adamu H, Erko B, Zhang L, Tilahun G. Multilocus genotyping of Giardia duodenalis isolates from children in Oromia special zone, central Ethiopia. BMC Microbiol. 2016;16:89.

31. Qi M, Yu F, Li S, Wang H, Luo N, Huang J, Zhang L. Multilocus genotyping of potentially zoonotic Giardia duodenalis in pet chinchillas (Chinchilla lanigera) in China. Vet Parasitol. 2015;208:113-7.

32. Solarczyk P, Majewska AC, Moskwa B, Cabaj W, Dabert M, Nowosad P. Multilocus genotyping of Giardia duodenalis isolates from red deer (Cervus elaphus) and roe deer (Capreolus capreolus) from Poland. Folia Parasitol (Praha). 2012;59:237-40.

33. Solarczyk P, Majewska AC. Prevalence and multilocus genotyping of Giardia from animals at the zoo of Poznan, Poland. Wiad Parazytol. 2011;57:169-73.

34. Sulaiman IM, Fayer R, Bern C, Gilman RH, Trout JM, Schantz PM, et al. Triosephosphate isomerase gene characterization and potential zoonotic transmission of Giardia duodenalis. Emerg Infect Dis. 2003;9:1444-52.

35. Azcona-Gutiérrez JM, de Lucio A, Hernández-de-Mingo M, García-García C, Soria-Blanco LM, Morales L, et al. Molecular diversity and frequency of the diarrheagenic enteric protozoan Giardia duodenalis and Cryptosporidium spp. in a hospital setting in northern Spain. PLoS One. 2017;12:e0178575.

36. Burland TG. DNASTAR's Lasergene sequence analysis software. Methods Mol Biol. 2000;132:71-91.

37. Thompson JD, Gibson TJ, Plewniak F, Jeanmougin F, Higgins DG. The CLUSTAL_X windows interface: flexible strategies for multiple sequence alignment aided by quality analysis tools. Nucleic Acids Res. 1997;25:4876-82

38. Adam RD. Biology of Giardia lamblia. Clin Microbiol Rev. 2001;14:447-75.

39. Olson ME, O'Handley RM, Ralston BJ, McAllister TA, Thompson RC. Update on Cryptosporidium and Giardia infections in cattle. Trends Parasitol. 2004;20:185-91.

40. Alexander C, Jones B, Inverarity D, Pollock KG. Genotyping of Giardia isolates in Scotland: a descriptive epidemiological study. Epidemiol Infect. 2014;142: $1636-9$

41. Armson A, Yang R, Thompson J, Johnson J, Reid S, Ryan UM. Giardia genotypes in pigs in Western Australia: prevalence and association with diarrhea. Exp Parasitol. 2009;12:381-3.

42. Farzan A, Parrington L, Coklin T, Cook A, Pintar K, Pollari F, et al. Detection and characterization of Giardia duodenalis and Cryptosporidium spp. on swine farms in Ontario, Canada. Foodborne Pathog Dis. 2011:1207-13.

43. Maddox-Hyttel C, Langkjaer RB, Enemark HL, Vigre H. Cryptosporidium and Giardia in different age groups of Danish cattle and pigs - occurrence and management associated risk factors. Vet Parasitol. 2006;141:48-59.

44. Petersen HH, Jianmin W, Katakam KK, Mejer H, Thamsborg SM, Dalsgaard A et al. Cryptosporidium and Giardia in Danish organic pig farms: seasonal and age-related variation in prevalence, infection intensity and species/ genotypes. Vet Parasitol. 2015;214:29-39.

45. Langkjaer RB, Vigre H, Enemark HL, Maddox-Hyttel C. Molecular and phylogenetic characterization of Cryptosporidium and Giardia from pigs and cattle in Denmark. Parasitology. 2007;134:339-50.

46. Stojecki K, Sroka J, Cencek T, Dutkiewicz J. Epidemiological survey in Łęczyńsko-Włodawskie Lake District of eastern Poland reveals new evidence of zoonotic potential of Giardia intestinalis. Ann Agric Environ Med. 2015:22: $594-8$. 
47. Minetti C, Taweenan W, Hogg R, Featherstone C, Randle N, Latham SM, Wastling JM. Occurrence and diversity of Giardia duodenalis assemblages in livestock in the UK. Transbound Emerg Dis. 2014;61:e60-7.

48. Budu-Amoako E, Greenwood SJ, Dixon BR, Barkema HW, Hurnik D, Estey C, McClure JT. Occurrence of Giardia and Cryptosporidium in pigs on Prince Edward Island, Canada. Vet Parasitol. 2012;184:18-24.

49. Schär F, Inpankaew T, Traub RJ, Khieu V, Dalsgaard A, Chimnoi W, et al. The prevalence and diversity of intestinal parasitic infections in humans and domestic animals in a rural Cambodian village. Parasitol Int. 2014;63:597-603.

50. Uysal HK, Boral O, Metiner K, Ilgaz A. Investigation of intestinal parasites in pig feces that are also human pathogens. Turkiye Parazitol Derg. 2009;33:218-21.

51. Hamnes IS, Gjerde BK, Forberg T, Robertson L. Occurrence of Cryptosporidium and Giardia in suckling piglets in Norway. Vet Parasitol. 2007;144:222-33.

52. Xiao L, Herd RP, Bowman GL. Prevalence of Cryptosporidium and Giardia infections on two Ohio pig farms with different management systems. Vet Parasitol. 1994:52:331-6.

53. Hashimoto A, Kunikane S, Hirata T. Prevalence of Cryptosporidium oocysts and Giardia cysts in the drinking water supply in Japan. Water Res. 2002;36:519-26.

54. Olson ME, Thorlakson CL, Deselliers L, Morck DW, McAllister TA. Giardia and Cryptosporidium in Canadian farm animals. Vet Parasitol. 1997;68:375-81.

\section{Submit your next manuscript to BioMed Central and we will help you at every step:}

- We accept pre-submission inquiries

- Our selector tool helps you to find the most relevant journal

- We provide round the clock customer support

- Convenient online submission

- Thorough peer review

- Inclusion in PubMed and all major indexing services

- Maximum visibility for your research

Submit your manuscript at www.biomedcentral.com/submit

) Biomed Central 